\title{
Morfologia macro e microscópica das papilas linguais do quati (Nasua nasua) ${ }^{1}$
}

\author{
Aline F. Souza ${ }^{2 *}$, Vanessa C. Oliveira ${ }^{2}$, Amilton C. Santos ${ }^{3}$, Ricardo A. Rosa ${ }^{4}$, Ana F. Carvalho ${ }^{4}$, \\ Carlos E. Ambrósio ${ }^{2}$ e Celina A.F. Mançanares ${ }^{2}$
}

\begin{abstract}
Souza A.F., Oliveira V.C., Santos A.C., Rosa R.A., Carvalho A.F., Mançanares C.A.F. \& Ambrósio C.E. 2012. [Gross and microscopic morphology of the coati tongue (Nasua nasua).] Morfologia macro e microscópica da língua de quati (Nasua nasua). Pesquisa Veterinária Brasileira 32(3):271-277. Departamento de Ciências Básicas, Faculdade de Zootecnia e Engenharia de Alimentos, Av. Duque de Caxias Norte 225, ZAB, Campus da USP, Pirassununga, SP 13870-000, Brazil. E-mail: alinesouza25@hotmail.com

The coati (Nasua nasua) is an animal that belongs to the Procyonidae family. For this study we used three orthotanasized animals of both sexes, obtained from the Scientific Center for Wild Animal Breeding, University Center Octavio Bastos Educational Foundation (Cecrimpas, Unifeob), authorized by IBAMA (Proc.02027.003731/04-76). For microscopic analysis, tongues were processed routinely through electron microscopy scanning and inclusion in Paraplast; for light microscopy, the fragments were cut by microtome with an average thickness of $5 \mathrm{~mm}$ and stained with H\&E and Picrosirius counterstained with hematoxylin. The macroscopic and microscopic results show that the tongue of coati has filiform, fungiform, vallate and conical papillae distributed in the rostralis, medialis and caudalis regions. Histologically, the tongue is lined by a keratinized stratified squamous epithelium with spinous, granulous and keratin basal layer, with striated longitudinal and transverse skeletal muscles fibers, and several glands. We can conclude that coati's tongue has macroscopic and microscopic features similar to the ones of Canidae, with differences in the number of vallate papillae and degree of keratinization.
\end{abstract}

INDEX TERMS: Morphology, carnivores, tongue, coati, Nasua nasua.

RESUMO.- O quati (Nasua nasua) é um animal que pertence à Família Procyonidae. Foram utilizados três animais ortotanasiados, de ambos os sexos, provenientes do Criatório Científico de Animais Silvestres, Centro Universitário Fundação de Ensino Octávio Bastos (Cecrimpas, Unifeob) autorizado pelo IBAMA (Proc.02027.003731/04-76). Para a análise macroscópica, as línguas foram retiradas, analisa-

\footnotetext{
${ }^{1}$ Recebido em 16 de setembro de 2011.

Aceito para publicação em 9 de fevereiro de 2012.

${ }^{2}$ Departamento de Ciências Básicas, Faculdade Zootecnia e Engenharia de Alimentos. Campus da Universidade de São Paulo (USP), Avenida Duque de Caxias Norte 225, ZAB, Pirassununga, SP 13636-900, Brasil. *Autor para correspondência: alinesouza25@hotmail.com. Outros autores: van.cristina.oliveira@hotmail.com, celina_furlanetto@hotmail.com

${ }^{3}$ Departamento de cirurgiasetor de anatomia dos Animais Domésticos e Silvestres, Faculdade de Medicina Veterinária e Zootecnia, USP, Av. Prof. Dr. Orlando Marques de Paiva 87, São Paulo, SP 05508-270, Brasil. E-mail: amiltonsantos@bol.com.br

${ }^{4}$ Departamento de Morfologia, Centro Universitário Fundação de Ensino Octávio Bastos, Av. Dr. Octávio Bastos (Unifeob), São João da Boa Vista, SP 13870000, Brasil. E-mails: ricardoalerosa@hotmail.com, anaflaviac@uol.com.br
}

das e foto-documentadas. Para análise microscópica, as línguas foram processadas rotineiramente pela técnica de microscopia eletrônica de varredura e inclusão em Paraplast; pela técnica de microscopia de luz os fragmentos foram cortados em micrótomo, com espessura média de $5 \mathrm{~mm}$ e corados em HE e Picrosírius com fundo de hematoxilina. Os resultados macroscópicos e microscópicos mostram que a língua do quati apresenta papilas filiformes, fungiformes, valadas e cônicas sendo estas distribuídas nas regiões rostralis, medialis e caudalis. Histologicamente, a língua do quati é revestida por um epitélio pavimentoso estratificado queratinizado apresentando camada basal, espinhosa, granulosa e córnea com fibras de músculos estriados esqueléticos longitudinais e transversais e diversas glândulas. De acordo com os resultados pode-se concluir que a língua do quati possui características macroscópicas e microscópicas semelhantes aos canídeos, tendo como diferença o número de papilas valadas e o grau de queratinização.

TERMOS DE INDEXAÇÃO: Morfologia, carnívoros, língua, quati, Nasua nasua. 


\section{INTRODUÇÃO}

A família Procyonidae pertence à ordem carnívora. Originalmente, essa é dividida em duas subfamílias: Procyoninae e Ailuriane (Teixeira \& Ambrósio 2007). Na América do Sul, encontram-se quatro gêneros: Procyon, Nasua, Potos e Bassaricyon (Denver 2003).

Segundo Beisiegel (2001) e Teixeira \& Ambrosio (2007), o quati (Nasua nasua) é um procionídeo que pode ser facilmente identificado pelo focinho longo que se destaca diante dos olhos, orelhas pequenas, e sua coloração está entre cinza e variações de marrom claro a marrom escuro. Conforme Chinem \& Avari (2010), são animas de hábitos diurnos, terrestres e arborícolas, possuem hábito alimentar onívoro e frugívoro. Sua distribuição geográfica está do leste dos Andes, a partir da Colômbia e Venezuela, em direção sul até a Argentina e Uruguai, no território nacional ocupam quase todas as regiões (Teixeira \& Ambrósio 2007).

A língua é um órgão muito importante para a realização de funções como: a mastigação, a deglutição e a fala e participa de estímulos funcionais que atuam no crescimento e no desenvolvimento da face (Bezerril et al. 2005). Segundo Ellenport (1981) e Gartner \& Hiatt (1999), a língua ocupa a maior parte da cavidade oral da boca e a sua extrema mobilidade é devida a uma grande massa de fibras musculares esqueléticas extrínsecos e intrínsecos.

Em geral, a língua possui pequenas saliências na superfície chamadas de papilas filiforme, fungiforme, valadas ou circunvaladas e foliadas no qual podem variar consideravelmente em tamanho, aparência, na forma, no número, distribuição e função (Butendieck \& Vargas 1998). Pelas diferentes características e morfologias que a língua e as papilas linguais apresentam e devido à escassez de literatura sobre a morfologia da língua do quati, este trabalho teve como objetivo caracterizar anatomicamente e morfologicamente as papilas linguais, para que possamos, através dos dados obtidos nesta pesquisa, adquirir melhores conhecimentos básicos deste sistema e compará-lo com outras espécies.

\section{MATERIAL E MÉTODOS}

Nesta pesquisa foram utilizados três animais (quatis) ortotanaziados provinientes do Criatório Científico de Animal Silvestre do Centro Universitário Fundação de Ensino Octávio Bastos (Unifeob) autorizado pelo IBAMA (Proc.02027.003731/04-76).

Os animais foram pré-anestesiados com acepran $3 \circledR 0,05 \mathrm{mg} /$ $\mathrm{kg}$ (IM), induzidos com pré anestesico Telazol $4{ }^{\circledR} 20 \mathrm{mg} / \mathrm{kg}$ (IV) e após alcançar o plano anestésico profundo, foi injetada uma ampola de cloreto de potássio 19,1\% (10ml) via intracardíca. Os animais foram canulados e fixados em solução de formaldeído a 10\%. Para a análise macroscópica, as línguas foram extraídas, dissecadas, retiradas da cavidade oral e as estruturas identificadas foram classificadas, desenhadas esquematicamente, analisadas e fotodocumentadas numa câmara digital Sony Mavica 3.2 Mp.

Para o processamento microscópico, segmentos de diferentes partes da língua (rostralis, medialis e caudalis) foram recortados e pós-fixados em solução de paraformaldeído a $4 \%$ em tampão fosfato de sódio. (Dulbecco's phosfate buffer saline-DPBS, Gibco Co., USA). Posteriormente o material foi desidratado em uma série de etanóis em concentrações crescentes (70\% a 100\%), diafanizado em xilol, seguido de inclusão em similar de parafina (Histo- sec $^{\circledR}$, Merk, lote: K91225309), cortados em micrótomo) Leica RM 2165 com espessura média de $5 \mathrm{~mm}$ (micrômetrose). Posteriormente os cortes foram corados por Hematoxilina eosina (HE) e Picrossírius com fundo de hematoxilina de Harris (Junqueira et al. 1979), montadas com Entelan $®$ e laminulas. A fotodocumentação microscópica foi feita através de um fotomicroscópio Leica DM 2000 e a nomenclatura utilizada foi referida conforme International Commitee on Veterinary Gross Histological and Anatomical Nomenclature (2005)

Para o processamento de microscopia eletrônica de varredura duas línguas de quati foram fixadas em glutaraldeído a 2,5\% por 36 horas e depois reduzido em três fragmentos (rostral, médio e caudal). Posteriormente foram lavados em tampão fosfato por 3 vezes e colocados em solução de ácido tânico a $2 \%$ durante duas horas à temperatura ambiente e lavado em tampão fosfato. Em seguida, o material foi pós-fixado em solução de tetróxido de Ósmio a 2\% durante 90 minutos. As amostras foram lavadas em tampão fosfato e, posteriormente em água destilada. 0 material ficou em imersão em acido tânico por meia hora e depois foi lavado em água destilada. As amostras passaram pelo processo de desidratação em álcool etílico em concentrações de 50\% (2x15 minutos); $70 \%$ (15 minutos); 80\% (15 minutos); 90\% (2x15 minutos) e $100 \%$ (4x15 minutos), posteriormente foi realizada a secagem em aparelho de ponto crítico Balzers, CPD-030, utilizando $\mathrm{CO}_{2}$ líquido. Os fragmentos foram montados em bases metálicas de alumínio (stubs) com cemento de carbono e cobertas com ouro $\mathrm{Au}$ ) através do aparelho Lom Sputter Balzer SCD - 040 e foram analisados em microscópio eletrônico de varredura Zeiss Leo 435 VP.

Os estudos foram realizados no Laboratório de Pesquisa Morfológica do Centro Universitário da Fundação de Ensino Octávio Bastos de São João da Boa Vista, (SP) e no da Faculdade de Medicina Veterinária e Zootecnia do Setor de Anatomia dos Animais Domésticos e Silvestres da Universidade de São Paulo.

\section{RESULTADOS}

Macroscopicamente pode-se observar que a língua do quati (Nasua nasua) esta localizada na parte ventralis da boca, de aspecto aveludado, coloração rósea, sendo mais larga na raiz afunilando-se em direção ao ápice rostralis. 0 seu tamanho em comprimento é de aproximadamente oito centímetros e três milímetros. A largura próxima à raiz é de três centímetros, o qual se estreita em direção à região cranialis, podendo medir um centímetro e meio. No ápice dorsalis da língua pode-se observar o sulco mediano lingual, com cerca de três centímetros de comprimento.

Em toda extensão da língua observou-se, quatro tipos de papilas: filiformes, fungiformes, valadas e cônicas (Fig.1A-D) e a ausência de papilas foliadas.

Os aspectos histológicos $r$ revelaram que a língua do quati apresenta-se revestida pelo epitélio pavimentoso estratificado, o qual apresenta uma camada basal, espinhosa, granulosa, córnea e uma camada muscular com feixes longitudinais e transversais (Fig.2A, B). No terço medialis e caudalis notou-se algumas glândulas salivares. 0 grau de queratinização era bastante variável, em relação às papilas, pois algumas se apresentam mais queratinizadas do que outras.

No ápice lingual encontramos uma distribuição de papilas finas (papilas filiformes) e outras arredondadas (papilas fungiformes). As papilas filiformes (Fig.2C) possuem aspecto espinhoso, não apresentam botões gustativos e 

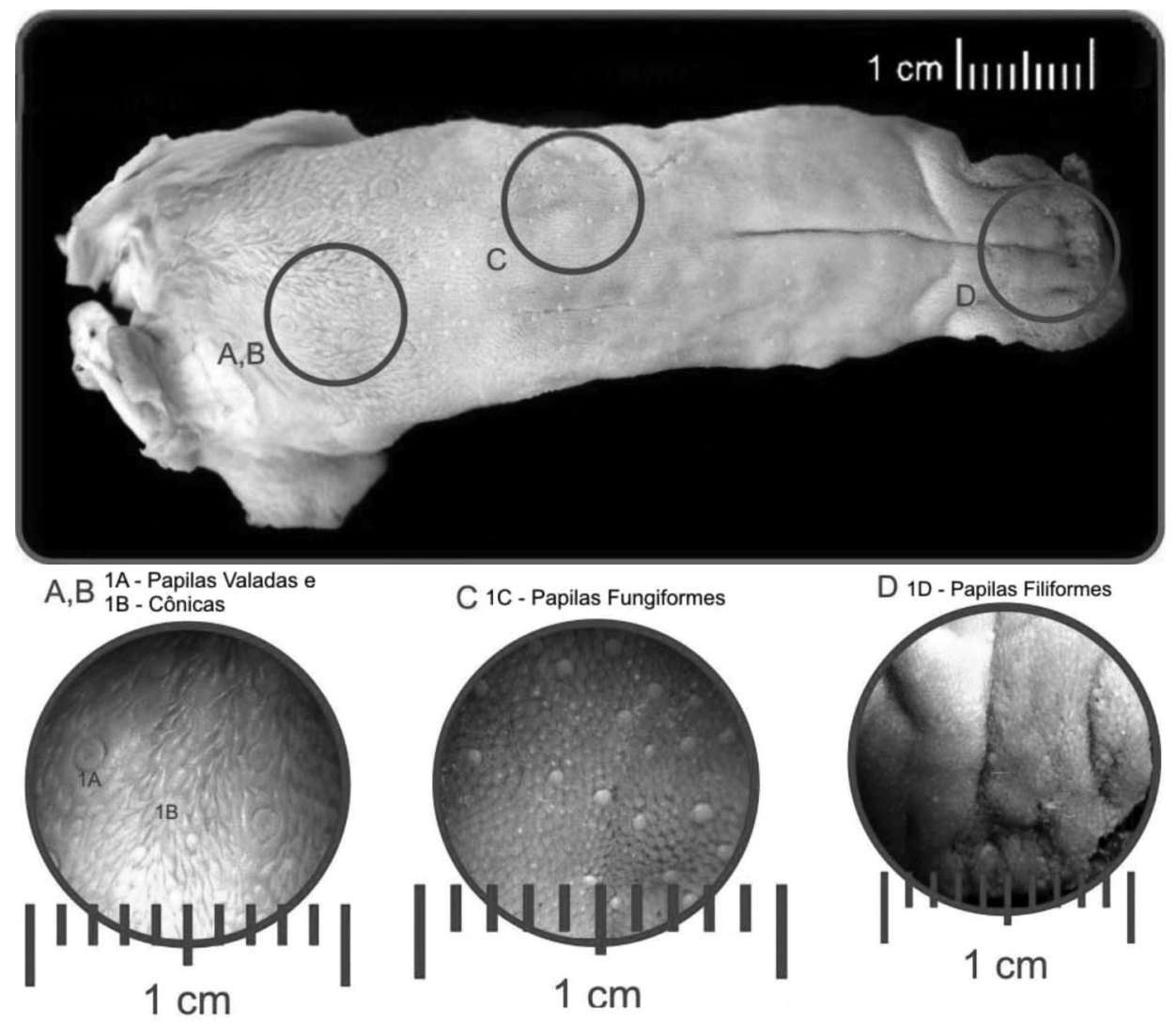

Fig.1. Língua do quati (Nasua nasua) em vista dorsal. (A) Papilas valadadas. (B) Papilas cônicas. (C) Papilas fungiformes. (D) Papilas filiformes.

algumas destas ficam entremeadas as papilas fungiformes (Fig.3A) e seu epitélio possui um aspecto queratinizado (Fig.2E).

As papilas fungiformes encontram-se no terço médio da mucosa (Fig.3C) estas possuem uma base estreita e uma parte apical dilatada. Histologicamente pode-se observar tecido conjuntivo denso com grande quantidade de tecidos adiposos e não relatou-se a presença de botões gustativos (Fig.3D).

Na região caudalis notou-se grande quantidade de glândulas salivares, serosas e mucosas e a presença de papilas valadas e papilas cônicas. As papilas valadas (Fig.4A) como o próprio nome sugere ficam localizadas dentro de uma depressão do epitélio lingual projetando-se um pouco acima da superfície da língua, com numerosos corpúsculos gustativos em sua parede lateral e juntamente como sulco desembocam papilas gustativas e glândulas salivares linguais serosas (glândula de von Ebner). Ao longo da raiz estão localizadas as papilas cônicas que se apresentam em forma de cone e são pouco queratinizadas (Fig.4C).

$\mathrm{Na}$ face dorsal da mucosa lingual, através da análise por microscópico eletrônico de varredura, observou-se grande quantidade de papilas linguais. $0 \mathrm{~A}$ região dorsalis revelou papilas filiformes e algumas fungiformes. As papilas filiformes estão distribuídas principalmente no ápice e na região mediana da língua e ausente na região caudalis, próximo à raiz (Fig.2D). As papilas fungiformes estão localizadas sobre o dorso e lateralmente a face dorsalis e ventralis da língua, entretanto encontram-se ausentes na base e na raiz, se entrelaçando com as papilas filiformes (Fig.3B).
Na região caudalis verifica-se a presença de duas papilas, uma com característica de vala profunda na qual seria a papila valada e outra com uma formação pontiaguda central, denominada papila cônica. Pode-se observar que a papila valada apresenta aberturas de ductos de glândulas salivares, além de forma arredondada e mediram cerca de três milímetros. Apresentam um total de nove papilas valadas, organizadas em um padrão " $\mathrm{V}$ " invertido, ou seja, afunilam próximo à raiz (Fig.4B). As papilas cônicas também são encontradas na direção da faringe e são de fácil visualização e entrelaça com as papilas valadas (Fig.4D).

\section{DISCUSSÃO}

De acordo com os resultados histológicos obtidos, com as colorações Hematoxilina e Eosina (HE) e Picrossírus com fundo de Hematoxilina, nota-se a camada epitelial da mucosa dorsalis da língua do Nasua nasua,a qual apresenta um epitélio pavimentoso com vários graus de queratinização.

Pode-se perceber no quati uma diferenciação entre as camadas de células epiteliais iniciando da camada basal à camada superficial queratinizada. Estruturas semelhantes foram descritas em animais carnívoros, inclusive o grau de queratinização do epitélio que reveste a mucosa da língua sendo estes muito variáveis, pois dependem muitas vezes dos hábitos alimentares do animal (Banks 1991, Junqueira \& Carneiro 2004, Samuelson 2007). Diferentemente dos trabalhos relatados em alguns mamíferos, como em "doninhas japonesas" (Mustela itatsi) que o epitélio lingual 

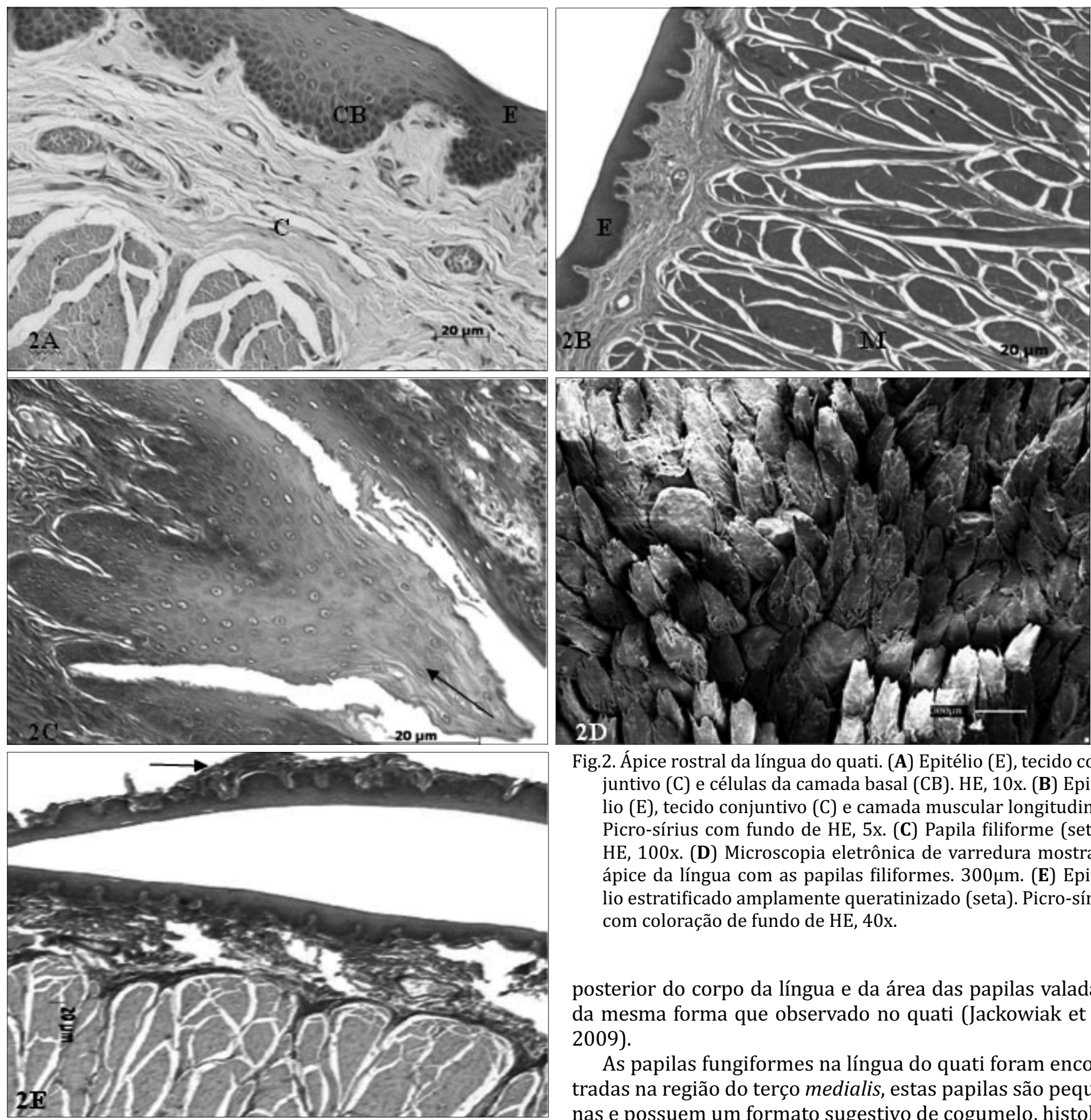

Fig.2. Ápice rostral da língua do quati. (A) Epitélio (E), tecido conjuntivo (C) e células da camada basal (CB). HE, 10x. (B) Epitélio (E), tecido conjuntivo (C) e camada muscular longitudinal. Picro-sírius com fundo de HE, 5x. (C) Papila filiforme (seta). HE, 100x. (D) Microscopia eletrônica de varredura mostra o ápice da língua com as papilas filiformes. $300 \mu \mathrm{m}$. (E) Epitélio estratificado amplamente queratinizado (seta). Picro-sírus com coloração de fundo de HE, 40x.

posterior do corpo da língua e da área das papilas valadas, da mesma forma que observado no quati (Jackowiak et al. 2009).

As papilas fungiformes na língua do quati foram encontradas na região do terço medialis, estas papilas são pequenas e possuem um formato sugestivo de cogumelo, histoloapresenta uma espessura de camada córnea com alto grau de queratinização (Furubayashi et al. 1989).

Como mostra os resultados, as papilas filiformes, como o nome indica, são estreitas e de forma filamentar, igualmente referido em carnívoros domésticos, a qual estas papilas apresentam-se cônicas e alongadas, são mais freqüentes, cobrindo toda a superfície dorsal da língua e não apresentam botões gustativos (Gartner \& Hiatt 1999, Junqueira \& Carneiro 2004,). Fonseca et al. (2011), em seu trabalho com Capra hircus relatou que as papilas filiformes estão densamente distribuídas na superfície dorsalis e lateralis, sendo que ao chegar ao toro lingual sua quantidade decresce consideravelmente. Enquanto que em raposas árticas (Alopex lago$p u s)$, as papilas filiformes sofrem uma redução entre a parte gicamente revelou um epitélio e tecido conjuntivo denso, fato também visto em carnívoros domésticos (Stinson \& Calhoun 1982, Banks 1991, Branco 2011). Nos resultados relatados por Emura et al. (2004), as papilas fungiformes do tigre possuem um aspecto de corpo arredondado e estão distribuídas mais densamente no ápice rostralis. Contudo,em Tayassu tajacu as papilas fungiformes são distribuídas aleotariamente na região média da língua, constituindo uma multicamada de epitélio e tecido conjuntivo denso, com fibras nervosas e vários capilares, contrapondo os nosso resultados no quati (Watanabe et al. 2011).

Conforme relatado por Pastor et al. (2011) a espécie Ursus americanus apresenta papilas fungiformes distribuídas entre as papilas filiformes e a espécie Tremarctos orna- 

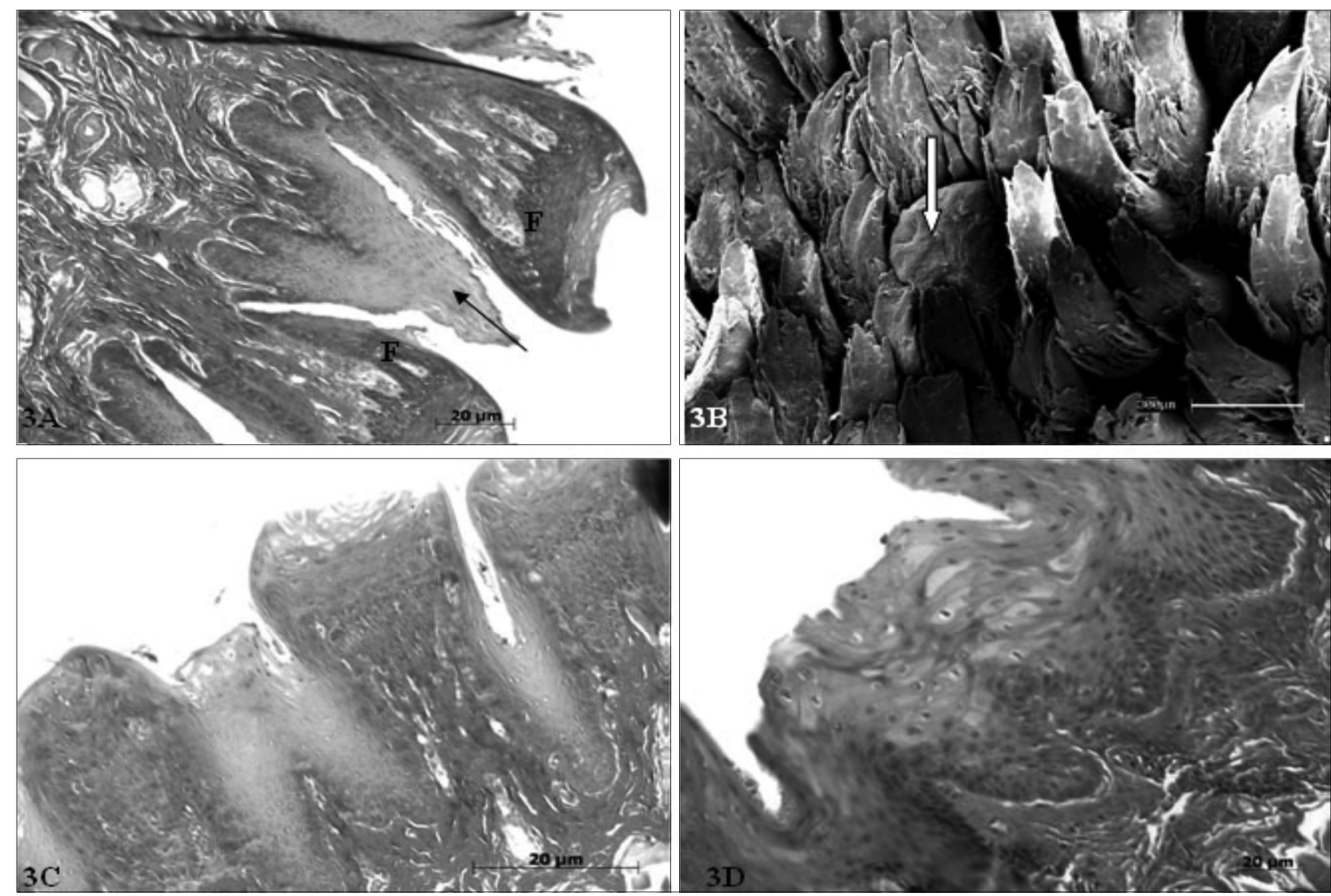

Fig.3. Terço rostral da língua do quati. (A) Papila filiforme (seta) entremeada a fungiforme (F). HE, 40x. (B) Microscopia eletrônica de varredura exibe a papila fungiforme (seta) rodeada pelas papilas filiformes. $300 \mu \mathrm{m}$. (C) Papilas fungiformes (F) não queratinizadas. (C) Epitélio estratificado pavimentoso pouco queratinizado. HE, 40x.

tus, apresenta uma maior concentração das papilas fungiformes na região medialis, concomitantemente observado no quati, porém em $U$. thibetanus e $U$. Malayanus as papilas fungiformes estão distribuídas ao longo de toda a superfície da língua. No quati estas papilas não apresentaram botões gustativos, fato diferente do descrito por Samuelson (2007) que notou que alguns animais carnívoros essas estruturas são mais facilmente encontradas.

Os resultados obtidos em nosso estudo demonstraram que na região caudalis encontra-se algumas papilas valadas. Nesta região as papilas eram maiores e mais largas que as demais observadas em outras regiões. Estas características também foram notadas por Branco et al. (2011) em Callithrix penicillata.

Ellenport (1981) descreveu que as papilas valadas variam muito de espécie para espécie, em cães normalmente existem duas ou três papilas em quaisquer dos lados caudalis ou dorsalis. Pastor et al. (2008) encontrou em pandas gigantes (Ailuropoda melanoleuca) um total de onze papilas valadas isoladamentes ou formando pares de papilas menores. Em macacos esquilos, Iawasaki et al. (1988) somente uma papila valada, e em leões marinhos (Zalophus californianus californianus (Yoshimura et al. 2002) cinco papilas, sendo que em nossos estudos notamos apenas nove destas papilas.
Ao observamos o epitélio das papilas valadas no quati, notamos grande quantidade de glândulas serosas e a presença de botões gustativos localizados ao longo de suas margens laterais, da mesma forma que descrito em carnívoros domésticos por Stinson \& Calhoun (1982), Banks (1991) e Gartner \& Hiatt (1999).

Os resultados mostram que as papilas cônicas são encontradas na direção da faringe, na região caudalis, era de fácil visualização e encontravam-se entremeadas com as papilas valadas, além de possuírem pouco grau de queratinização. Masuko et al. (2005), mostra que em raposas, as papilas cônicas estão presentes na raiz da língua e na região das papilas circunvaladas, e seu ápices voltados caudalmente, sendo mais volumosas e espessas na raiz da língua, próximo a epiglote, evento também descrito por Jackowiak et al. (2004), em raposa prateada (Alopex lagopus), tal qual observados no quati, em que as papilas cônicas estão localizadas na área das papilas valadas, recobrindo a parte posterior da raiz da língua e aumentando o tamanho em direção à faringe, onde são distribuídos mais esparsamente.

\section{CONCLUSÃO}

Conclui-se que a língua do quati (Nasua nasua) possui características macroscópicas e microscópicas semelhantes 

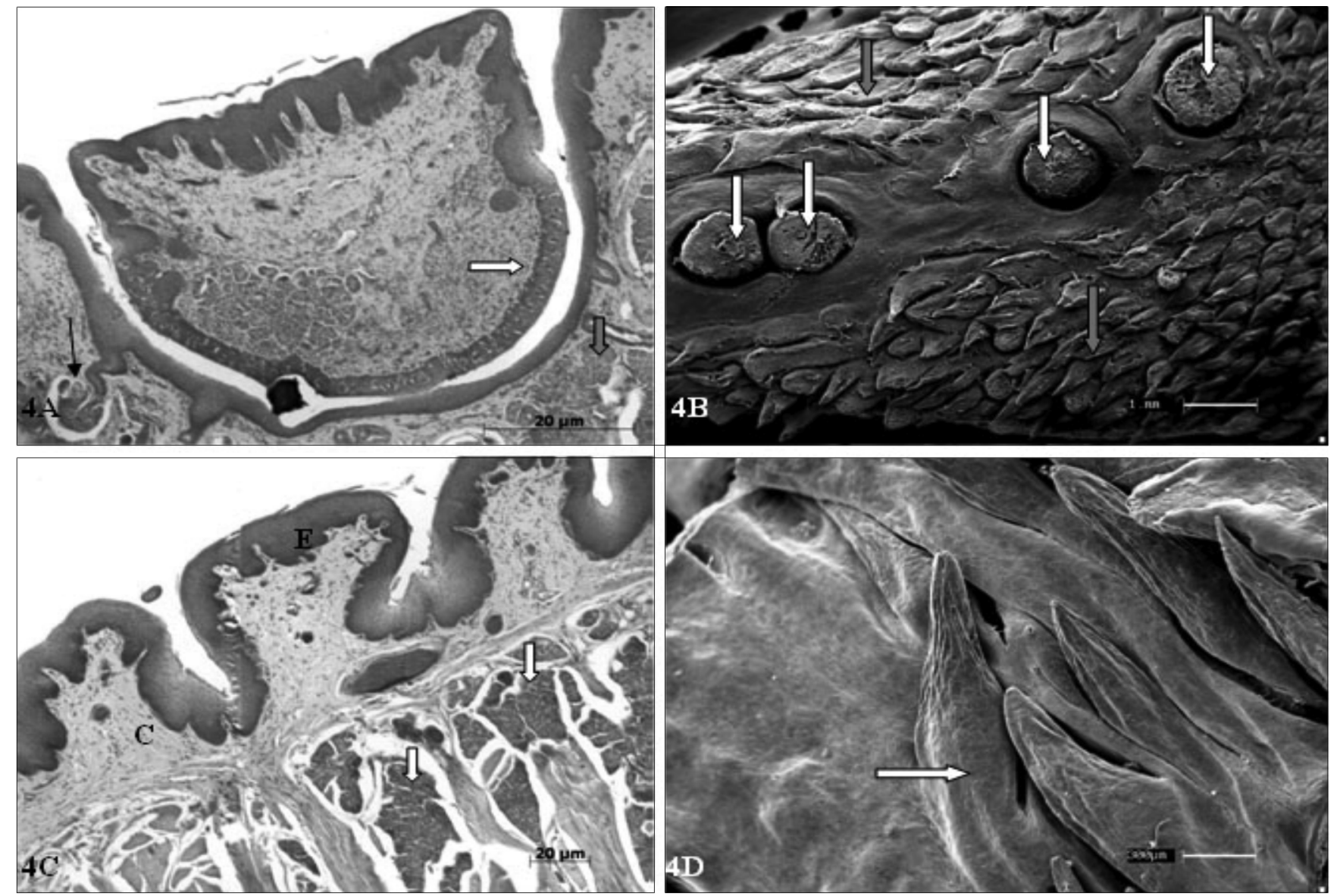

Fig.4. Terço caudal rostral da língua do quati. (A) Papila valada, os corpúsculos gustativos (seta larga), glândulas serosas (seta vermelha), glândula de von Ebner (seta fina). HE, 100x. (B) Microscopia eletrônica de varredura as papilas valadas (seta branca) e as papilas cônicas (seta vermelha).1nn. (C) A papila cônica com epitélio estratificado pavimentoso queratinizado (E), tecido conjuntivo (C) e grande concentração de glândulas mucosas (seta larga). HE, 40x. (D) Microscopia eletrônica de varredura das papilas cônicas (seta branca). $300 \mu \mathrm{m}$.

aos dos carnívoros domésticos, tendo como diferença o grau de queratinização e o número de papilas valadas.

\section{REFERÊNCIAS}

Banks W.J. 1991. Histologia Veterinária Aplicada. 2ª ed. Manole, São Paulo. 629 .

Beisiegel B.M. 2001.Notes on the coati, Nasua nasua (Carnivora: Procyonidae) in an Atlantic Forest area. Braz. J. Biology, São Carlos, 61:4.

Bezerril D.D., Barreto J., Macari S. \& Felicio C.M. 2005. A língua: características morfológicas normais e alterações. JBP Revta Ibero-Am. Odontopediatr. Odontol. bebê 8(43):264-270.

Branco E., Pereira W.L., De Lima A.R., Franciolli A.L., Rici R.E., Miglino M.A., Muniz J.A. \& Imbeloni A. 2011. Ultrastructural aspects of Callithrix penicillata lingual papillae. Microscopy Research and Technique. DOI. 10.1002/jemt.21055

Butendieck E.M.V. \& Vargas L. 1998. Presencia y distribucion de las papilas linguales en la alpaca (Lama pacos Linnaeus, 1758). Arch. Med. Vet. 30(2):29-36.

Chinem S. \& Avari R. Quati. Disponível em <http://www.zoologico.sp.gov. $\mathrm{br} /$ mamiferos/quati.htm> Acesso $10 \mathrm{fev} .2010$.

Denver M. 2003 Procionidae and Viverridae, p.516-523. In: Fowler M. \& Miller R.E. (Eds), Zoo and Wild Animal Medicine. W.B. Saunders, Missouri. 782p.

Ellenport C.R. 1981. Sistema digestivo do carnívoro, p.1445. In: Getty R. (Ed.), Anatomia dos Animais Domésticos. Ed. Interamericana, Rio de Janeiro. 2000p.
Emura S., Hayakawa D., Chen H. \& Shoumura S. 2004. Morphology of the lingual papillae in the tiger. Okajimas Folia Anat. Jpn. 81:39-44.

Fonseca E.T., Oliveira C.M., Franciolli A.L.R. \& Miglino M.A. 2011. Características das papilas o dorso da língua de cabras (Capra hircus): estudo por de microscopia eletrônica de varredura e luz. Pesq. Vet. Bras. 31:6773

Furubayashi R., Sato E, \& Ishibashi T.1989. Histological pattern of the tongue in the Japanese weasel, Mustela itatsi, with special references to the morphology and distribution of papillae, taste buds and lingual glands. Acta Anat. Nippon. 64:210-214.

Gartner L.P. \& Hiatt J.L. 1999. Tratado de Histologia em Cores. Guanabara Koogan, Rio de Janeiro. 426p.

Iawasaki S., Myata K. \& Kobayashi K.M. 1988. Scanning electron microscopic study of the dorsal lingual surface of the squirrel monkey. Acta Anatomica 132:225-229.

International Comittee on Veterinary Gross Anatomical Nomenclature. 2005. Nomina Histologica Veterinaria. $2^{\text {nd }}$ ed. Editorial Committee Hannover, Columbia. 166p.

Jackowiak H., Godynicki S., Skieresz-Szewczyk K. \& Trzcielinska-Lorych J. 2009. Scanning electron microscopic study of the lingual papillae in the arctic fox (Alopex lagopus L., 1758). Anatomia, Histologia, Embryologia 38:377-38.

Jackowiak H. \& Godynicki S.2004. The scanning electron microscopic study of lingual papillae in the silver fox. Ann. Anat. 186:179-183.

Junqueiara L.C.V., Bignonas G. \& Bretan R.P. 1979. Picrosirius staing plus polarization microscopy, a specific method for collagen detection in the tissue sections. Histochem. J. 11:4:447-455. 
Junqueira L.C. \& Carneiro J. 2004. Histologia Básica. Guanabara Koogan, Rio de Janeiro. 488p.

Masuko T.S., Menezes D.J.A. \& Barros A.A. 2005. Estudo mesoscópico das papilas linguais de raposa. Reunión de Integración de la Morfología Panamericana: Resúmenes. Int. J. Morphol. 23(1):45-94. (Online)

Pastor F.J., Barbosa M., De Paz F.J. \& Ferrero E. 2011. Functional and comparative study of lingual papillae in four species of bear (Ursidae) by scanning electron microscopy. Microscopy Research and Technique 74(10):910-919.

Pastor F.J., Barbosa M. \& De Paz F.J. 2008. Morphological study of the lingual papillae of the giant panda (Ailuropoda melanoleuca) by scanning electron microscopy. J. Anatomy 212:99-105.

Samuelson A.-Don. 2007. Tratado de Histologia Veterinária. Elsevier, Rio de Janeiro. 527p.
Stinson A.W. \& Calhoun M.L. 1982. Sistema digestivo, p.166-169. In: Dellmann H.D. \& Brown E.M. (Eds), Histologia Veterinária. Guanabara Koogan, Rio de Janeiro. 397p.

Teixeira R.H.F. \& Ambrósio S.R. 2007. Carnívora - Proyonidae, p.571-573. In: Cubas Z.S., Silva J.C.R. \& Dias J.C. (Eds), Tratado de Animais Selvagens. Roca, São Paulo.1354p.

Watanabe I., Guimarães J.P., Maia M.O., Santos T.C., Kfoury J.R. Jr, Boleta S.A., Almeida S.R., Righeti M.M. \& Miglino M.A. 2011. SEM and neurohistological observations of nerve endings in the middle region of the tongue of the collared peccary (Tayassu tajacu): a silver impregnation method. Anat Histol. Embryol. 40(2):128-33.

Yoshimura K., Shindoh J. \& Kobayashi K. 2002. Scanning electron microscopy study of the tongue and lingual papillae of the California sea lion (Zalophus californianus californianus). Anat. Rec. 267:146-153. 